\title{
Um diálogo entre a Filosofia e a Química: uma proposta didática para o ensino de atomística a partir do livro o Mundo de Sofia
}

\author{
A dialogue between Philosophy and Chemistry: a didactic proposal for the \\ teaching of atomistics from the book The Word of Sofia
Um diálogo entre Filosofía y Química: una propuesta didáctica para la enseñanza de la atomística del libro El mundo de Sofía

\author{
Antônio de Pádua Arruda dos Santos Filho (apasf95@ hotmail.com) \\ Instituto Federal de Educação, Ciência e Tecnologia do Ceará - campus Fortaleza. \\ Maria Cleide da Silva Barroso (ccleideifcemaraca@gmail.com) \\ Instituto Federal de Educação, Ciência e Tecnologia do Ceará. \\ Carolina de Goes Sampaio (carol-quimica@ hotmail.com) \\ Instituto Federal de Educação, Ciência e Tecnologia do Ceará.
}

Resumo: Pesquisas na área da filosofia da ciência tem evidenciado diversos obstáculos para que propostas de ensino sejam concretizadas. Diante deste cenário, o presente artigo pretende sugerir uma proposta de ensino sobre a filosofia da química para ser desenvolvida com alunos do 9: ${ }^{\circ}$ Ano do Ensino Fundamental e 1: Ano do Ensino Médio, tendo como ferramenta principal o livro o Mundo de Sofia. Para a construção do trabalho foi realizado um estudo bibliográfico, de caráter exploratório. O trabalho foi dividido em cinco sessões, onde a primeira conceitua e descreve como a filosofia da química tem sido construída; a segunda faz uma síntese do livro e destaca o capítulo principal a ser usado; a terceira descreve sobre quem foi Demócrito, considerado um grande filosofo e químico; a quarta explica sobre o seu conceito de atomística, e a última apresenta a proposta de ensino e como deve ser aplica. Por fim, conclui-se que a área da filosofia da química nos últimos anos vem ganhado destaque no campo da filosofia da ciência, e percebido também uma carência de pesquisas e propostas para o ensino, por ser um livro rico com bastante assuntos a serem analisados.

Palavras-chave: Filosofia da Química; O mundo de Sofia; Demócrito; Átomo; Ensino.

Abstract: Research in the area of philosophy of science has highlighted several obstacles for teaching proposals to be implemented. Against this backdrop, this article intends to suggest a teaching proposal on the philosophy of chemistry to be developed with students of the 9th year of elementary school and 1st year of high school, having as main tool the book The World of Sofia. For the construction of the work, a bibliographic study of exploratory character was carried out. The work was divided into five sessions, where the first conceptualizes and describes how the philosophy of chemistry has been built; the second makes an overview of the book and highlights the main chapter to be used; the third describes who democritus was considered a great philosopher and chemist; the fourth explains about its concept of atomistics, and the latter presents the teaching proposal and how it should be Recebido em: 17/05/2021

Aceite em: $31 / 08 / 2021$ 
applied. Finally, it is concluded that the area of philosophy of chemistry in recent years has gained prominence in the field of philosophy of science, and also perceived a lack of research and proposals for teaching, because it is a rich book with enough subjects to be analyzed.

Keywords: Philosophy of Chemistry; The world of Sofia; Democritus; Atom; Teaching.

Resumen: La investigación en el área de la filosofía de la ciencia ha puesto de relieve varios obstáculos para que las propuestas de enseñanza se implementen. En este escenario, este artículo pretende sugerir una propuesta de enseñanza sobre la filosofía de la química que se desarrollará con los estudiantes a partir de 9. Escuela primaria y 1. ${ }^{\circ}$ Año de bachillerato, teniendo como principal herramienta el libro el Mundo de Sofía. Para la construcción de la obra se realizó un estudio bibliográfico de carácter exploratorio. El trabajo se dividió en cinco sesiones, donde la primera conceptualiza y describe cómo se ha construido la filosofía de la química; el segundo hace una visión general del libro y destaca el capítulo principal a utilizar; el tercero describe quién fue considerado un gran filósofo y químico; el cuarto explica sobre su concepto de atomística, y el segundo presenta la propuesta de enseñanza y cómo debe aplicarse. Por último, se concluye que el área de filosofía de la química en los últimos años ha ganado protagonismo en el campo de la filosofía de la ciencia, y también se percibe una falta de investigación y propuestas para la enseñanza, porque es un libro rico con suficientes temas para ser analizados.

Palabras-clave: Filosofía de la Química; El mundo de Sofía; Demócrito; Átomo; Enseñanza.

\section{INTRODUÇÃO}

A filosofia da química é uma extensão disciplinar da filosofia da ciência, foi instituída em 1994, após serem realizados diversos eventos em países como, Inglaterra, Alemanha e Itália. Ao longo do século XX, a filosofia da ciência, estava restrita exclusivamente ao estudo lógico e sintético da ciência ideal, e no contexto do neopositivismo, secundarizou a filosofia da química. Todavia, no presente momento, é a área que tem gerado mais resultados na filosofia da ciência (RIBEIRO; BEJARANO; SANTOS, 2012, p. 2). Pois, a química, além de ser dinâmica, é também uma ciência ancorada por um ambiente de aplicabilidade, onde os químicos, estando aproximados da experimentação, desenvolvem um trabalho tanto teórico como prático, fazendo com que as concepções químicas alcancem sentidos importantes (SILVA et al, 2018, p. 404).

Conhecimentos interligados envolvendo a filosofia da ciência aparecem na literatura especializada como meios pertinentes para favorecer a transdisciplinaridade abrangendo conhecimentos científicos, metacientíficos e artístico, combinando a dimensão teórica da 
aprendizagem curricular com a dimensão formativa e cultural (FORATO; MARTINS; PIETROCOLA, 2012, p. 124).

Tendo em conta a relação criada entre a Filosofia da Química e o Ensino de Química, pode-se entender que o modo de pensar sobre a natureza do conhecimento químico contribuirá para o aprendizado de concepções químicas (SILVA et al, 2018, p. 413).

Um meio para poder ser abordado a Filosofia da Química no Ensino de Química, é através da utilização de livros paradidáticos, pois Laguna (2012, p. 43) explica que os livros paradidáticos tem a finalidade de estimular nas pessoas o prazer pela leitura, comprovando o ato de ler como sendo eficaz para ensinar. Vale, Coelho e Venuto (2020, p. 461) acrescentam evidenciando que livros paradidáticos favorecem no desenvolvimento de estudos que são embasados nas questões culturais, históricas e sociais que cercam o assunto que está sendo estudado, fazendo que tanto o professor como aluno investiguem uma realidade que muitas vezes ainda é desconhecida. Devido a isso, que será adotado o livro paradidático o Mundo de Sofia como ferramenta para o ensino de Química.

O mundo de Sofia é um livro que foi lançado em 1991 pelo escritor Jostein Gaarder, autor de diversos livros de romances filosóficos. O livro foi traduzido para mais de sessenta línguas, e só na Alemanha foi constado a venda de quatro milhões de exemplares (CARNEIRO, 2018, p. 1). O livro possui trinta e cinco capítulos, onde o autor utiliza de qualquer recurso que esteja a sua disposição para facilitar a compreensão de um pensamento filosófico, como, por exemplo, peças de Lego para ajudar na explicação sobre o pensamento atômico de Demócrito (GAARDER, 2012). E é neste capítulo que esta pesquisa quer focar.

Demócrito era uma pessoa diferente, mas tinha ideias perspicazes e, além disso, aprendera com o seu professor, o filósofo Leucipo, e realizara melhorias, com a ajuda de seus alunos, a um novo fundamento. Isso foi definido por um olhar da realidade como um composto de partículas infinitesimais, invisíveis e indivisível: os átomos. A ciência atual veio para confirmar que toda matéria é composta de átomos, apesar de que ela não conceda as essas partículas as mesmas características que Demócrito propôs-lhes. Mesmo assim, sua ideia, sustenta a explicação racional de como a realidade que conhecemos surge de compostos formados a partir da união de átomos (MILANI, 2006, p. 11, tradução nossa).

Estudos tem revelado, em diferentes âmbitos, obstáculos e desafios para serem efetivadas propostas concretas sobre a filosofia da ciência. Possibilitar que os conteúdos da 
filosofia da ciência se tornem apropriados à educação básica exige-se que aconteça uma transformação de nicho epistemológico. Não é suficiente apenas acrescentar conteúdos de filosofia da ciência na sala de aula, sem reconhecer que qualquer atividade educativa espelha as concepções que os docentes têm sobre o trabalho científico, repassando, de modo implícito ou explicito, uma visão sobre a natureza da ciência (FORATO; MARTINS; PIETROCOLA, 2012, p. 123-127).

No Ensino de Química, percebe-se que um dos maiores obstáculos a serem superados é o da inserção de novas metodologias de ensino, sendo ainda pertinente o ensino tradicional, modelo este unidirecional, em que o professor é o único transmissor de conhecimento e o aluno, este muitas vezes não podendo dar a sua opinião sobre o assunto que está sendo estudado. Nesse contexto, a ludicidade pode desempenhar um papel importante para o desenvolvimento de novos meios de ensinar química, auxiliando ao estudante a ampliar o seu modo de pensar, ampliando e enriquecendo sua formação (BENEDETTI FILHO et al, 2020, p. 221).

Desse modo, o presente artigo tem a finalidade de sugerir uma proposta para o ensino de química direcionada as séries de $9 .^{\circ}$ Ano do Ensino Fundamental e $1 .^{\circ}$ Ano do Ensino Médio que trabalhe a Filosofia da Química, de modo que os estudantes possam despertar interesse pela área estudada.

\section{METODOLOGIA}

A pesquisa é de natureza aplicada, de caráter exploratório, onde se desempenhou um estudo bibliográfico, utilizando como principais fontes os trabalhos desenvolvidos por Cartledge (2001), Milane (2006), Anastasiou e Alves (2007), Gaarder (2012) e o Rozentalski (2018).

Prodanov e Freiras (2013, p. 51) explicam que a natureza da pesquisa do posto de vista aplicado, tem a finalidade de estimular a criação de novos conhecimentos necessários para o desenvolvimento da ciência com aplicabilidade direcionada para a solucionar problemas específicos.

Sobre o caráter exploratório, Gil (2008, p. 27) esclarece que, a pesquisa exploratória tem o objetivo de propiciar uma visão geral sobre um determinado assunto. Prodanov e Freiras (2013, p. 51) contribui expondo que, a pesquisa exploratória é quando a pesquisa está Recebido em: $17 / 05 / 2021$ 
na fase inicial, e que tem o objetivo de propiciar mais esclarecimentos sobre o tema que vai ser investigado, tornando possível sua descrição e delimitação. A pesquisa exploratória, em geral, assume a forma de pesquisa bibliográfica.

Severino (2017, p. 136) esclarece que a pesquisa bibliográfica é aquela elaborada a partir de referências já disponíveis, decorrente de estudos realizados anteriormente. Gil (2008, p. 50) acrescenta argumentando que a pesquisa bibliográfica é vantajosa por possibilitar ao pesquisador o alcance de uma série de ocorrências bem mais desenvolvidas do que aquela que poderia ser investigada de modo mais direto.

O critério considerado para a escolha das principais fontes bibliográficas para a construção desse artigo foi o de serem obras completas sobre os tópicos que iriam ser abordados. Sendo os livros de Cartledge (2001) e Milane (2006), dois referenciais completos no que diz respeito a vida do filósofo Demócrito; o artigo da Anastasiou e Alves (2007) por apresentar diversas técnicas de ensinagem, possibilitando assim, a criação de uma proposta de ensino; Gaarder (2012) por ser o autor do livro O Mundo de Sofia; e Rozentalski (2018), por ser uma tese sobre a Filosofia da Química.

O Artigo enfim, foi dividido em cinco partes para que sua leitura seja bem compreendida, sendo a primeira sobre a filosofia da química, a segunda uma síntese do livro O mundo de Sofia, a terceira uma biografia do filósofo e químico Demócrito, a quarta uma explicação sobre a sua teoria atômica, e a última, a proposta para o ensino de química.

\section{FILOSOFIA DA QUÍMICA}

A Filosofia da Química destina-se a estudar os inúmeros fenômenos pertencentes a área da química, a ontologia de entidades das quais se considera que tais fenômenos façam parte, e questões epistemológicas (JUSTI; GILBERT, 2002, p. 213, tradução nossa). Sjöström (2006, p. 11, tradução nossa) corrobora explicando que a filosofia da química pesquisa sobre a natureza da química e suas extensões curriculares, tais como os conceitos epistemológicos, metodológicos, pensamentos metafísicos, cultural, identitário, ético e estético.

Durante o século XX, discussões e conceitos referentes a química não era de interesse filosófico. O número de filósofos das ciências que se debruçaram sobre a Química foram poucos. Um dos principais fatores para isso foi que os problemas filosóficos relacionados a Química, podiam, em último caso serem estudados pela Filosofia da Física. 
(ROZENTALSKI, 2018, pp. 154-155). Scerri (2000, tradução nossa) acrescenta que outro fator considerável para não se ter iniciado pesquisas sobre a filosofia da química foi por existir, da parte de ambos, um menosprezo, no mínimo, uma indiferença.

Ribeiro e Pereira (2013, p. 1832) acrescentam que a química é uma ciência incomodada com parâmetros classificatórios e norteada pelo raciocínio prático. Ela utiliza a concepção diagramática, simbólica, relacional, procedimental e heurística. A química recebe influência de princípios estéticos, em especial os de criação e inovação, ela depende de muitos equipamentos e métodos. E devido a isso, se existia pouco interesse em estudar a filosofia da química. Isto, influenciou para que a Filosofia da Química não tenha começado a ser estudada tão cedo como foi com a Filosofia da Física.

Contudo, mesmo que os químicos tenham argumentos para debater que as questões filosóficas não são necessárias para as suas atividades, as relações entre Química e Filosofia não são só capazes de acontecerem, mas são inescusáveis (ROZENTALSKI, 2018, p. 156). E devido a isso, na década de 90 químicos, historiadores da química, filósofos e educadores começaram a demonstrar importância em se discutir questões filosóficas ligadas à área da química. Ribeiro (2017, p. 34) evidencia que países como a Alemanha, Itália e Holanda se esforçaram para isso acontecer.

Rozentalski (2018, p. 156) corrobora com o surgimento da Filosofia da Química, quando diz que “existem problemas filosóficos próprios da Química que não são redutíveis à Filosofia da Física, e que reflexões sobre tais problemas deveriam ser originados pela e por meio da própria Química.” Labarca, Bejarano e Eichler (2013, p. 1263) acrescentam que a Química pela sua própria natureza, contém fundamentos específicos, considerando a abrangência de substâncias existentes e a enorme variedade de reações que conseguem realizar. Ribeiro (2016, p. 219) completa expondo que o ano de 1994 é considerado um dos principais anos para a institucionalização da Filosofia Química. Visto que nesse ano foram realizados encontros internacionais em Largue, Londres, Marbug e em Roma.

Rozentalski (2018, p. 158) apoiando-se em outros autores, apresenta uma série de áreas que a Filosofia da Química tem realizado estudos:

A Filosofia da Química tem produzido reflexões sobre conceitos fundamentais da Química, como, por exemplo: substância simples, composto (substância composta), afinidade, reação química, átomo, estrutura molecular e aromaticidade (Schummer, 2006). Além disso, a Filosofia da Química tem analisado os métodos químicos, que podem ser divididos em: i) métodos práticos, tais como experimentação,

Recebido em: $17 / 05 / 2021$

Aceite em: $31 / 08 / 2021$ 
instrumentação e síntese química; e ii) métodos cognitivos, tais como a linguagem pictórica da química e inúmeras formas de construção de modelos e representação (ibid.). Além desses tópicos, Scerri e McIntyre (1997) indicam outros tópicos investigados pela Filosofia da Química, tais como a natureza da explicação química, as leis químicas, e a noção de superveniência, que indica as relações entre o macroscópico e o microscópico.

Tendo em conta o que já foi discutido até o momento, e, tomando como fundamento a tese de Rozentalski (2018), faz-se necessário levantarmos três questionamentos acerca do ensino de Filosofia em Química: para quem, para quê, o que ensinar e como ensinar Filosofia da Química?

O ensino de Filosofia da Química é destinado para pessoas que não tem o desejo de se tornarem licenciados ou bacharéis em Filosofia. Devido a isso, os professores de Filosofia da Química devem ter em mente que o conteúdo ensinado será direcionado para químicos e professores de química, então será de suma importância um planejamento, pois quando isso é descartado o modo como é abordado o conteúdo poderá gerar dificuldades de compreensão, podendo surgir indagações sobre o porquê de tal conteúdo ser importante para sua formação (ROZENTALSKI, 2018, p. 173-174).

A Filosofia da Química tem o objetivo de formar profissionais críticos e reflexivos, capazes de formarem pensamentos próprios a partir da e sobre a Química. É de particularidade da Filosofia da Química um estilo característico de pensar, o qual não é formado a partir de opiniões, mas articulando teorias com o objetivo de entender a Química. (ROZENTALSKI, 2018, p. 175-176)

O mesmo autor (2018, p. 176) ainda acrescenta que:

\begin{abstract}
A Filosofia da Química na Educação Química não deve ser considerada como a única abordagem preocupada em promover o pensamento crítico e reflexivo. Todas as disciplinas, aulas e abordagens da formação em Química devem se orientar para tal desenvolvimento. Cada qual tem assuntos, conceitos, práticas e objetivos próprios na formação; contudo, em última instância, devem pretender esse objetivo mais amplo e fundamental.
\end{abstract}

Se temos o propósito de ter uma disciplina integralmente voltada para a Filosofia da Química, os conteúdos (questões, assuntos, teorias, concepções, etc.) precisam ser escolhidos conforme o objetivo da aula, grau de desenvolvimento do aluno, organização do curso, etc. Dessa forma, estaremos em maior ou menor estágio, a depender das razões citadas, ensinando 
a Filosofia da Química, mesmo que esta não esteja sendo feita por filósofos e para filósofos da Química. Os assuntos não visam ter um fim, mas pretendem estimular a crítica e a reflexão, estabelecendo circunstâncias para os alunos desempenharem suas próprias experiências filosóficas (ROZENTALSKI, 2018, p. 180-181). E a partir dessas experiências compreender conceitos científicos químicos.

\section{O MUNDO DE SOFIA}

Próximo de completar quinze anos, Sofia Amundsen, uma garota norueguesa, começa a ganhar bilhetes e cartões-postais com mensagens bastantes estranhas. Os bilhetes não possuem remetente e neles possuem perguntas como: “Quem é você?”. Já os cartões-postais são enviados do Líbano para uma certa garota chama Hilde Møller Knag por um major misterioso, a quem Sofia não imagina nem quem seja a garota e o tal major. A incógnita sobre os bilhetes e os cartões-postais é a largada desta narrativa fascinadora, que vem atraindo milhões de leitores por todo o mundo. A cada capitulo, o leitor é chamado a explorar toda a história da filosofia ocidental, em simultâneo, em que se vê envolto de uma história que ganha um rumo surpreendente (GAARDER, 2012).

O mundo de Sofia se fosse um livro de suspense ou ficção, no estilo dos best-sellers normais, seria compreensível entender o seu sucesso de venda, sobretudo entre o público infanto-juvenil, mas estamos falando de um livro sobre Filosofia. Na verdade, o livro consegue unir estas três temáticas literárias como enredo para apresentar a história da filosofia, em uma linguagem mais simples, chamativa, logica e aprofundada (SANTOS, 1996, p. 48).

Carneiro (2018, p. 1) corrobora com tal afirmativa quando diz que, a história de O Mundo de Sofia não seria uma história capaz de se tornar um best-seller entre os adolescentes. Ela descreve o livro como sendo denso, e que, na verdade, é um livro de filosofia, que tem como um dos principais objetivos falar sobre os filósofos ocidentais. "É um livro de ruptura, e esse elemento atravessa toda a narrativa, desperta no leitor a dúvida e coloca em xeque papeis que aparentemente estavam consolidados."

O capítulo cinco do livro tem como título "Demócrito" e como subtítulo “[...] o brinquedo mais genial do mundo [...]”, em um de seus parágrafos é descrito a seguinte situação:

Recebido em: $17 / 05 / 2021$

Aceite em: $31 / 08 / 2021$ 
Subiu para o quarto e abriu o envelope lá mesmo. Dessa vez havia um bilhete com apenas uma pergunta, que acabava sendo ainda mais maluca do que as três perguntas escritas na "carta de amor": Por que o Lego é o brinquedo mais genial do mundo? (GAARDER, 2012, p. 55-56).

O capítulo apresenta a pessoa de Demócrito (c. 460-370 a.C.) como o último filósofo da natureza. Demócrito imaginou a constituição das coisas como sendo partículas indivisíveis, minúsculas, eternas e imutáveis e as deu o nome de átomos. Estes, do seu ponto de vista, possuíam várias formas, se diferenciavam entre si, poderiam ser reaproveitadas. Por exemplo, se um animal falecesse, seus átomos iriam participar da constituição de outros corpos. Era exatamente por isso que o Lego era o brinquedo mais genial do mundo. Ele podia ser usado para a construção de diversos objetos, estando a cargo da imaginação das pessoas. Era um brinquedo resistente e "eterno", pois em qualquer época, as crianças gostavam de brincar com o Lego. Demócrito valorizou a razão e as coisas materiais. Não acreditava em forças que pudessem vir interver nos processos naturais, achavam também que sua teoria atômica esclarecia as nossas percepções sensoriais e que a consciência e alma também eram constituídas de átomos. Ele não acreditava na ideia de alma imortal (GAARDER, 2012, p. 57$60)$.

O livro O Mundo de Sofia apresenta em apenas um capítulo poucas informações sobre quem foi Demócrito, pois o foco principal do capítulo é apresentar a analogia entre o átomo e o jogo de Lego, contudo, é importante conhecer mais sobre a vida deste filósofo para conseguir entender sua ideia sobre o átomo.

\section{DEMÓCRITO: FILÓSOFO E QUÍMICO}

A tradição conta que na cidade de Abdera, já no limite de Trácia, ao norte de Atenas, no século V a.C., viveu um personagem curioso, diziam que a todas as situações da vida ele reagia com um sorriso. Fosse em um funeral ou em uma reunião, ele estaria sorrindo, pois, considerava que não haveria nada do ser humano que valesse a pena levar a sério. Seus conterrâneos devem ter o considerado como sendo uma pessoa louca. O personagem em questão, nada mais é que Demócrito, um discípulo de Leucipo, embora pertencesse a uma família rica, ele não estava interessado nos bens que herdou de seu pai. Todo o dinheiro herdado, ele gastou fazendo viagens, das quais voltou sem dinheiro, mas como o mesmo dizia, rico em conhecimento. Alguns de seus contemporâneos passaram a admira-lo pela Recebido em: $17 / 05 / 2021$ 
forma como levava a vida, e devido a isso, conquistou vários discípulos, podemos citar: Metrodorus de Kyo, Nessa de Kyo, e um dos mais importantes, Hipócrates de Cos, considerado o pai da medicina ocidental (MILANI, 2006, p. 10, tradução nossa).

Não se sabe com exatidão a data da natalidade de Demócrito, por não existir uma concordância nos inúmeros depoimentos encontrados sobre ele. Contudo, sobre seu falecimento, as fontes encontradas possuem uma certa concordância, relatando que o filósofo morreu com cerca de noventa a cento e oito anos (MILANI, 2006, p. 42-43, tradução nossa).

Historiadores descrevem que Demócrito ocupava um cargo público, tal afirmativa é supostamente comprovada por moedas datadas de 414 a.C. que possuíam a seguinte legenda: "no período de Demócrito" (CARTLEDGE, 2001, p. 2). Além disso, Demócrito também era entusiasta por viagens, sobre estas DK (68, A1 apud MILANI, 2006, p. 43, tradução nossa) descreve que Demócrito viajou por todo o Oriente, onde prevalecia as tradições religiosascientíficas. Diógenes expõe que ele foi ao encontro dos sacerdotes do Egito para estudar geometria, visitou os caldeus na Pérsia e o Mar Vermelho. Alguns outros pesquisadores dizem que ele também esteve na Índia com os gimnosofistas e que foi para a Etiópia.

As viagens que Demócrito realizou devem ter sido muito caras, ele só conseguiu pagálas devido a uma herança familiar. $\mathrm{Na}$ divisão da herança, ele deixou a maior parte do patrimônio imóvel e os campos, que eram as partes mais importantes da herança, para os seus dois irmãos mais velhos, e ficou apenas com o dinheiro, que iria servi-lo para pagar as viagens, no entanto, ele acabou desperdiçando tudo e se tornou praticamente pobre, o que o teria impedido de receber um enterro digno em sua terra natal (MILANI, 2006, p. 43, tradução nossa).

“Atribuir uma ligação oriental a Demócrito não só é politicamente correto, quanto ao do discurso acadêmico atual, mas é também certo quanto aos intelectuais e históricos." Demócrito era um dos principais detentores de conhecimentos da sua época, um filósofo nobre, mas também um pensador com aptidão em alto grau para a parte prática. Demócrito foi físico, cosmólogo, geólogo e medico, um filósofo ético e político, um pensador inconfundível e significativo. Atualmente ele é conhecido devido suas ideias sobre o átomo, considerado como um atomista pur sang ${ }^{1}$, devido a esse fato, é citado na Ciência (CARTLEDGE, 2001, p. 3-4).

\footnotetext{
${ }^{1}$ Tradução: puro-sangue

Recebido em: $17 / 05 / 2021$

Aceite em: $31 / 08 / 2021$
} 


\section{TEORIA ATÔMICA DE DEMÓCRITO}

A Química nos condicionou a imaginar o átomo como algo muito concreto, porém os atomistas da antiguidade não pensavam sobre o átomo da mesma forma que nós. Cogitar que o mundo era composto de átomos tinha para Demócrito não apenas um significado químico, mas também ontológico, ou seja, refletia o nosso ser (MILANI, 2006, p. 55, tradução nossa).

Segundo Demócrito, o átomo é inalterável e indestrutível, logo, é eterno. O átomo, no que diz respeito ao $\operatorname{arche}^{2}$ da realidade, não pode ser destruído, porquê senão toda a realidade seria destruída. O que pode ser destruído é a ligação entre átomos que formam as distintas manifestações da realidade (MILANI, 2006, p. 56, tradução nossa).

Na visão de Demócrito a natureza de todas as coisas são os átomos e o vazio. Contudo, não é possível conhecer a natureza das coisas, mas apenas as qualidades são resultantes dos compostos atômicos, como a cor, o odor, as sensações térmicas, características dos fenômenos, que então são observados pelos indivíduos. Mas esses fenômenos, com essas características são apenas aparências, que não demonstram a natureza dos sujeitos. De modo sucinto, são ideias. Ao passo que na época de Demócrito ainda são consideradas ideias, não puderam ser elevadas ao nível de verdades. Os sentidos nos encaminham a entender os fenômenos, mas estes são instáveis e não verdadeiros. Desse modo, Demócrito exclui os sentidos como fonte do verdadeiro conhecimento, o que só conseguiria acontecer pela razão (ALBINATI, 2005, p. 5). O que viria a ser estudado de modo mais aprofundado por John Dalton quando propôs o primeiro conceito de átomo aceito pela comunidade científica, em 1808.

A descrição mais longa da teoria atômica de Demócrito está contida em um escrito de Simplício, um analista extemporâneo do filósofo Aristóteles, que seria uma citação do ensaio de Aristóteles sobre Demócrito:

Demócrito julga que a natureza das coisas eternas consiste em pequenas substâncias, infinitas em quantidade, e, para elas, postula um lugar, distinto delas e infinito em extensão. Ele chama os lugares com os nomes de "vazio", "nada" e "infinito"; e cada uma das substâncias, denomina de "coisa", "sólido" e "ser". E julga que as substâncias são tão pequenas que elas escapam dos nossos sentidos, e que elas possuem toda espécie de formas e toda espécie de figuras e diferenças de tamanho.

\footnotetext{
${ }^{2}$ Elemento fundamental que, para os filósofos pró-socráticos, compõe e dá origem ao Universo, encontrado a partir da natureza (physis), geralmente se refere ao que é comum e subjacente a todas as coisas.
}

Recebido em: 17/05/2021

Aceite em: $31 / 08 / 2021$ 
Destas, como de elementos, ele pôde gerar e compor corpos visíveis e perceptíveis. Os átomos se agitam e são arrebatados no vazio por causa das dissimilaridades e das outras diferenças mencionadas, e, conforme eles se movem de um lado para outro, colidem e se enlaçam num entrelaçamento tal que faz com que se toquem e se tornem contíguos uns aos ou- tros. Mas isso não produz genuinamente qualquer outra natureza singular a partir deles; pois seria completamente tolo pensar que duas ou mais coisas possam tornar-se uma só coisa. Ele explica como as substâncias permanecem juntas em razão da maneira como os corpos se embaraçam e se agarram uns aos outros; pois alguns deles têm lados irregulares, alguns são em forma de gancho, alguns côncavos, alguns convexos, e outros têm inúmeras outras diferenças. Julga, portanto, que eles se agarram uns aos outros e permanecem juntos até que uma força externa mais poderosa os arranca de seu ambiente, os agita e dispersa. Fala da geração e do seu contrário, da dissolução, não só em relação aos animais, mas também às plantas e aos mundos - em suma, em relação a todos os corpos perceptíveis (D/K A37; B p.247-8 apud CARTLEDGE, 2001, p. 6).

Nesta descrição, as ideias sobre os átomos, proposto por Demócrito, conforme citado no livro o Mundo de Sofia, se assemelham às peças de Lego, devido à sua habilidade de rearranjo para formar diferentes elementos, enquanto são formados da mesma matéria fundamental.

\section{A UTILIZAÇÃO DE TÉCNICAS DE ENSINAGEM E DO JOGO DE LEGO} PARA ENSINAR A TEORIA ATÔMICA DE DEMÓCRITO: UMA PROPOSTA PARA O ENSINO DE FILOSOFIA DA QUÍMICA

A transdisciplinaridade entre Química e Filosofia é algo que já vem sendo estudado a alguns anos e proposto por alguns pesquisadores. Labarca, Bejarano e Eichler (2013, p. 1256), utilizando um conceito químico, descrevem que a química e a filosofia são miscíveis, ou seja, podem se misturar. Lemes e Porto (2013, p. 135) corroboram com tal pensamento explicando que devido a isso a interação entre filosofia e química pode gerar uma relação favorável e simbiótica. Ribeiro (2016, p. 231) acrescenta expondo que uma aproximação entre a química e a filosofia consegue melhor explicar a práxis química, e dessa forma possivelmente sugerirá um currículo baseado em seu modo de analisar, expor e interpretar o mundo.

A Base Nacional Comum Curricular (2018, p. 556) na sua segunda competência, já propõe o conteúdo de filosofia da ciência: "nessa competência específica, podem ser mobilizados conhecimentos conceituais relacionados a história e filosofia das ciências." Desse 
modo, a ideia proposta para ensinar a teoria atômica de Demócrito utilizando um livro de filosofia passa a ser algo possível.

Com isso, a metodologia pensada para o desenvolvimento desta proposta de ensino deve ser aplicada em turmas do 9. ${ }^{\circ}$ Ano do Ensino Fundamental e 1. ${ }^{\circ}$ Ano do Ensino Médio, devido serem séries que estão tendo seu primeiro contato direto com as disciplinas de química e filosofia. A proposta de ensino possui quatro etapas: 1. Apresentação do livro O Mundo de Sofia; 2. Leitura do capítulo 5 do livro; 3. Explanação sobre o capítulo e explicação sobre quem é Demócrito; 4. Utilização do Lego para explicar o que é o átomo.

Para a realização da primeira etapa, faz-se necessário ao professor que for aplicar, ter lido o livro o Mundo de Sofia, pois é fundamental ele ter conhecimento e domínio sobre como a história no livro é desenvolvida. Nesta primeira fase, o discente deverá apresentar para os alunos, o livro, fazendo uma síntese geral, despertando assim a aproximação do aluno com a história do livro.

Livros paradidáticos, sendo a categoria de livro em que O Mundo de Sofia está enquadrado, de acordo com Fernandes e Melo (2019, p. 137), procuram oferecer conteúdos mais lúdicos e contextualizados para todos os níveis de ensino, contudo um dos principais objetivos dos mesmos é ensinar. Laguna (2012, p. 48) explica que os livros paradidáticos atendem a todas as disciplinas, buscando auxiliar os docentes e a enriquecer a vida dos estudantes. Silva e Carneiro (2019, p. 8) complementam argumentando que, os livros paradidáticos são alternativas de instrumentos pedagógicos e, que se utilizados pelos professores de maneira eficiente, proporcionará uma compreensão da Química como Ciência.

Para a segunda etapa, sugerimos a utilização de duas técnicas de ensinagem, ficando a critério do professor qual ele considera melhor para sua turma, sendo elas: estudo do texto e dramatização.

Anastasiou e Alves (2007) elucidam que o estudo de texto é a investigação de concepções de um escritor a partir da análise crítica de um texto, e poder ser aplicado em momentos de associação, construção e elaboração de síntese. Já a dramatização é uma atuação teatral, a partir de um tema, situação, etc. Podendo haver explanação de conceitos, ideias e ser também um modo diferenciado de estudo de caso $^{3}$, já que a teatralização de uma circunstância

\footnotetext{
${ }^{3} \mathrm{O}$ estudo de caso é uma categoria de pesquisa que busca investigar um acontecimento que está inserido dentro de uma situação real, quando os limites entre o acontecimento e a situação não estão nitidamente explicados, onde possuem vários indícios (GIL, 2008, p. 58).
}

Recebido em: $17 / 05 / 2021$

Aceite em: $31 / 08 / 2021$ 
ou um problema, diante dos alunos, corresponde a exibir uma ocorrência de relações humanas.

É uma estratégia que tem várias finalidades. Possibilita o desenvolvimento da "empatia", isto é, a capacidade de os estudantes se colocarem imaginariamente em um papel que não seja o seu próprio. Traz à sala de aula um pedaço da realidade social, de forma viva e espontânea, para ser observada e analisada pelos estudantes. Desenvolve a criatividade, a desinibição, a inventividade e a liberdade de expressão (ANASTASIOU; ALVES, 2007).

Na terceira fase, em que deve ser apresentado o conteúdo sobre Demócrito e o seu pensamento sobre o átomo, sugerimos a utilização da técnica aula expositiva dialogada. Anastasiou e Alves (2007) esclarecem que esta estratégia vem sendo sugerida para suplantar a tradicional palestra do professor. É fundamental entendermos que esta estratégia possui diferenças do modo de ensino tradicional, uma das principais diferenças é a participação do discente, que terá seus argumentos considerados, analisados e respeitados, independentemente da origem e da importância deles, sobre o conteúdo discutido.

A estratégia é desenvolvida através da exposição do conteúdo com as cooperações diretas dos estudantes, deve se considerar os conhecimentos prévios dos alunos, estes podem ser tomados como ponto inicial. O professor leva os estudantes a fazerem questionamentos, interpretações e debaterem sobre o objeto de estudo, partindo da observação e do embate com a realidade. Para esta estratégia, é preciso proporcionar a análise crítica, fazendo que gere resultados na produção de novos conhecimentos.

A última etapa desta proposta de ensino consiste na utilização do jogo de Lego para explicar como é o átomo de Demócrito. Portanto, antes de descrevermos como se dará esta etapa, é necessário conhecermos um pouco sobre o objeto que será utilizado.

O jogo de Lego, possui uma característica simples, sendo um objeto de construção, denominado de "bloco" ou "bloquinho". As peças de Lego podem ser combinadas de forma horizontal, vertical ou diagonal, em qualquer ângulo. Agrupados com pequenas figuras, elas podem reproduzir um cenário qualquer (KAWAHARA, 2019, p. 16).

Lasmar Filha et al (2013, p. 231) expõe que:

Os encaixes da Lego ${ }^{\circledR}$, por exemplo, são mais que simples brinquedos e podem ser uma importante ferramenta pedagógica, desde o ensino fundamental até a universidade. A sua popularidade passa ultrapassa as gerações, além de ser um brinquedo recomendado por educadores e terapeutas nas mais diversas áreas do conhecimento. 
Desse modo, após aplicado às três etapas anteriores, o professor pode levar para sala de aula o jogo de Lego separado por cores, indicando para cada cor um elemento químico, por exemplo, o Hidrogênio pode ser representado pela cor branca, o Oxigênio pela vermelha, o Carbono pela preta e o Nitrogênio pela azul. Após realizada esta apresentação, o discente deverá realizar combinações entre as peças de lego e mostrando como seria a combinação de elementos para formar compostos, por exemplo, duas peças brancas mais uma vermelha formando $\mathrm{H}_{2} \mathrm{O}$, ou uma peça preta mais duas azuis formando $\mathrm{CO}_{2}$.

Vale destacar que o professor ao trabalhar essa proposta, precisa deixar explicitado para o aluno que as cores que ele poderá usar para representar os elementos não representa de fato a cor original do elemento, para que isso não gere dúvida para o aluno. Outro ponto importante, é que o docente deverá também deixar esclarecido que o Lego não possui de fato o formato de átomo. Pois, como explica Lara (2014, p. 36) os estudantes muitas vezes confundem as analogias feitas, e acabam que passam a entender como se fosse uma definição propriamente dita do conceito a ser estudado, o mesmo destaca que isso acontece, sobretudo, quando está sendo feita analogias para se compreender modelos atômicos.

\section{CONSIDERAÇÕES FINAIS}

A elaboração do presente artigo possibilitou efetuar um estudo sobre a Filosofia da Química, como ela tem se construído no decorrer dos últimos anos e apresentar um meio para a sua aplicação com alunos do ensino básico.

Atualmente tem se percebido o aumento do interesse de químicos e filósofos das ciências pelos problemas que dizem respeito a química, e isto deriva um expressivo avanço da área da filosofia da química. Os estudiosos da área do ensino de química e da filosofia da química, defendem ser de suma importância que seja incluída questões que possam gerar criticidade no ensino. Para ocorrer, precisa que todos os níveis de ensino sejam reestruturados, desde o ensino básico aos cursos de licenciatura em química.

O processo realizado entre o estudo teórico e a elaboração de uma proposta de ensino é tão envolvente quanto complexo. É, então, indispensável que possua uma perspectiva transdisciplinar para o conhecimento. Não se refere a diferentes modos de se estudar um 
mesmo objeto, mas de realizar uma transposição, ou seja, mudar sua posição, neste caso além de ocorrer uma esta mudança, faz mais necessário uma união entre a química e a filosofia.

Durante a realização da pesquisa, foi perceptível a carência de estudos e aplicações utilizando o livro O Mundo de Sofia, tendo em vista ser um material rico em informações. O livro supracitado é um elemento importante e significativo para professores de filosofia, sociologia e história utilizarem nas suas aulas.

A prerrogativa defendida é que a proposta sugerida, poderá possibilitar resultados favoráveis, pois a pesquisa se situa no ambiente da práxis em sala de aula e ainda, constituem uma alternativa para que outros pesquisadores possam utilizar o método como estudo de caso.

\section{REFERÊENCIAS}

ALBINATI, Ana Selva. Marx, leitor de Demócrito e Epicuro. Verinotio-Revista on-line de Filosofia e Ciências Humanas, n. 3, p. 1-30, 2005. Disponível em: http://www.verinotio.org/sistema/index.php/verinotio/article/view/28/18

ANASTASIOU, L. G. C.; ALVES, L. P. Estratégias de Ensinagem. In: Processos de ensinagem na universidade: pressupostos para as estratégias de trabalho em aula. 7.ed. Joinville, SC: Univille, 2007.

BENEDETTI FILHO, E.; CAVAGIS, A.; BENEDETTI, L.; JÚNIOR, J.; JACOB, A. Uso de um mapa conceitual adaptado envolvendo atividades lúdicas para o ensino de Química. Revista Insignare Scientia - RIS, v. 3, n. 2, p. 220-236, 24 ago. 2020. Disponível em: https://periodicos.uffs.edu.br/index.php/RIS/article/view/11280/7476

BRASIL. Ministério da Educação. Base Nacional Comum Curricular: educação é a base. Brasília, DF, 2018. Disponível em: http://basenacionalcomum.mec.gov.br/images/BNCC_EI_EF_110518_versaofinal_site.pdf

CARNEIRO, Leticia Neri. A fuga da narrativa: autoria e leitura em O mundo de Sofia. 2018. Trabalho de Conclusão de Curso (Licenciatura em Letras Português) - Universidade de Brasília, Brasília, DF, 2018. Disponível em: https://bdm.unb.br/bitstream/10483/22585/1/2018_LeticiaNeriCarneiro_tcc.pdf

CARTLEDGE, Paul. Demócrito e a Política Atomista. São Paulo: Editora UNESP, 2001.

FERNANDES, K. S.; MELLO, I. C. de. Panorama das publicações brasileiras sobre paradidáticos no ensino de química. In: PORTELA, K. C. A.; SCHUMACHER, A. J. (org). Produção científica e experiências exitosas na educação brasileira 5. Ponta Grossa, PR: Atena Editora, 2019. Disponível em: https://www.atenaeditora.com.br/wpcontent/uploads/2019/08/E-BOOK-Producao-Cientifica-e-Experiencias-Exitosas-naEducacao-Brasileira-5-1-1.pdf

Recebido em: $17 / 05 / 2021$

Aceite em: $31 / 08 / 2021$ 
FORATO, T. C. M.; MARTINS, R, A.; PIETROCOLA, M. Enfrentando obstáculos na transposição didática da história da ciência para a sala de aula. In: PEDUZZI, L.Q.; MARTINS, A. F. P.; FERREIRA, J. M. H. (org.). Temas de História e Filosofia da Ciência no Ensino. Natal: EDUFRN, 2012. p. 123-154. Disponível em:

https://ppgect.ufsc.br/files/2012/11/Temas-de-Historia-e-Filosofia-da-Ciencia-no-Ensino1.pdf

GAARDER, Jostein. O mundo de Sofia: romance da história da filosofia. 1. ed. São Paulo: Companhia das Letras, 2012.

KAWAHARA, Samuel. O uso de blocos de lego: uma proposta para a construção de conhecimentos históricos. 2019. Trabalho de Conclusão de Curso (Especialista em Inovação e Tecnologias na Educação) - Universidade Tecnológica do Paraná, Curitiba, PR, 2019. Disponível em:

http://repositorio.utfpr.edu.br/jspui/bitstream/1/19639/1/CT_INTEDUC_I_2019_42.pdf

LASMAR FILHA, E. S. et al. Os jogos como ferramenta pedagógica universitária: um estudo de caso da utilização do Lego ${ }^{\circledR}$. Revista EDUCAmazônia - Educação Sociedade e Meio Ambiente, vol. 9, no. 2, p. 230-253, 2017. Disponível em: https://periodicos.ufam.edu.br/index.php/educamazonia/article/view/4594/3722

GIL, Antonio Carlos. Métodos e técnicas de pesquisa social. 6. ed. São Paulo: Atlas, 2008.

JUSTI, Rosária S; GILBERT, John K. Philosophy of chemistry in university chemical education: the case of models and modelling. Foundations of Chemistry, vol. 4, p. 213-240, 2002. https://doi.org/10.1023/A:1020608215725

LABARCA, Martín; BEJARANO, Nelson; EICHLER, Marcelo Leandro. Química e filosofia: Rumo a uma frutífera colaboração. Quimica Nova, vol. 36, no. 8, p. 1256-1266, 2013. https://doi.org/10.1590/S0100-40422013000800027.

LAGUNA, Alzira Guiomar Jerez. A contribuição do livro paradidático na formação do alunoleitor. Augusto Guzzo Revista Acadêmica, vol. 0, no. 2, p. 43, 2012. https://doi.org/10.22287/ag.v0i2.81.

LEMES, Anielli Fabiula Gavioli; PORTO, Paulo Alves. Introdução à filosofia da química: uma revisão bibliográfica das questões mais discutidas na área e sua importância para o ensino de química. Revista Brasileira de Pesquisa em Educação em Ciências, vol. 13, no. 3, p. 121-147, 2013. Disponível em: https://periodicos.ufmg.br/index.php/rbpec/article/view/4274/2839

MILANI, Claudia. Leucipo y Demócrito: los primeros atomistas descubrir la filosofía. 2006

PRODANOV, C. C.; FREITAS, E. C. Metodologia do trabalho científico: métodos e técnicas da pesquisa e do trabalho acadêmico. 2. ed. Novo Hamburgo: Feevale, 2013.

RIBEIRO, M. A. P.; BEJARANO, N. R. R.; SANTOS, J. A. Filosofia da Química como fundamento do ensino de Química. XVI Encontro Nacional de Ensino de Química e X Encontro de Educação Química da Bahia, 2012. Disponível em:

Recebido em: $17 / 05 / 2021$

Aceite em: $31 / 08 / 2021$ 
https://periodicos.ufba.br/index.php/anaiseneq2012/article/view/7701/5309

RIBEIRO, Marcos Antonio Pinto; PEREIRA, Duarte Costa. Constitutive Pluralism of Chemistry: Thought Planning, Curriculum, Epistemological and Didactic Orientations. Science and Education, vol. 22, no. 7, p. 1809-1837, 2013. https://doi.org/10.1007/s11191011-9434-4.

RIBEIRO, Marcos Antonio Pinto. A emergência da Filosofia da Química como campo disciplinar. Revista Brasileira de Pesquisa em Educação em Ciências, v. 16, n. 2, p. 215 236, 2016. Disponível em: https://periodicos.ufmg.br/index.php/rbpec/article/view/4373/2939

RIBEIRO, Marcos Antonio Pinto. Panorama histórico da relação entre Filosofia e Química. Educação Química en Punto de Vista, v. 1, n. 2, 2017. Disponível em: https://revistas.unila.edu.br/eqpv/article/view/977/814

ROZENTALSKI, Evando Fortes. Indo além da natureza da ciência: o filosofar sobre a química por meio da ética química. Tese (Doutorado em Ensino de Química) -

Universidade de São Paulo. Faculdade de Educação, Instituto de Física,Instituto de Química e Instituto de Biociências, São Paulo, 2018. Disponível em:

https://www.teses.usp.br/teses/disponiveis/81/81132/tde-16072018-

141205/publico/Evandro_Fortes_Rozentalski.pdf>

SANTOS, Simone Rios Bambirra. " O mundo de Sofia" no CEFET-MG. Educação \&

Tecnologia, v. 1, n. 3, 2011. Disponível em: https://seer.dppg.cefetmg.br/index.php/revistaet/article/view/184/185

SCERRI, E. The Failure of Reduction and How to Resist the Disunity of the Sciences in the Context of Chemical Education. Science \& Education, vol. 9, no. 5, 405-425. 2000. https://doi.org/10.1023/A:1008719726538

SEVERINO, Antônio Joaquim. Metodologia deo trabalho científico. 2. ed. São Paulo: Cortez, 2017

SILVA, C. M. S.; CARNEIRO, I. M. S. P. A contribuição do livro paradidático para o processo de ensino-aprendizagem de química no ensino médio. In: CONGRESSO NACIONAL DE EDUCAÇÃO, 6., 2019, Fortaleza. Anais eletrônicos. Ceará: Editora Realize, 2019. Disponível em: https://www.editorarealize.com.br/editora/anais/conedu/2019/TRABALHO_EV127_MD1_S A16_ID10938_15082019104820.pdf

SILVA, Lisandro Bacelar et al. A Filosofia da Ciência e a Filosofia da Química: Uma Perspectiva Contemporânea. Revista Ideação, 2018. Disponível em: http://periodicos.uefs.br/index.php/revistaideacao/article/view/3020/2394

SJÖSTRÖM, Jesper. Beyond Classical Chemistry. Chemistry International, no. October, 2006. Disponível em: http://old2015.iupac.org/publications/ci/2006/2805/2805-pp9-13.pdf

VALE, Ricardo Ferreira; COELHO, Gracielle Teodora da Costa Pinto; VENUTO, Marina Lanza. Os (multi) letramentos e a interdisciplinaridade no ensino de Microbiologia. Revista Recebido em: $17 / 05 / 2021$

Aceite em: $31 / 08 / 2021$ 
Insignare Scientia-RIS, v. 3, n. 5, p. 456-469, 2020. Disponível em: https://periodicos.uffs.edu.br/index.php/RIS/article/view/11904/7591

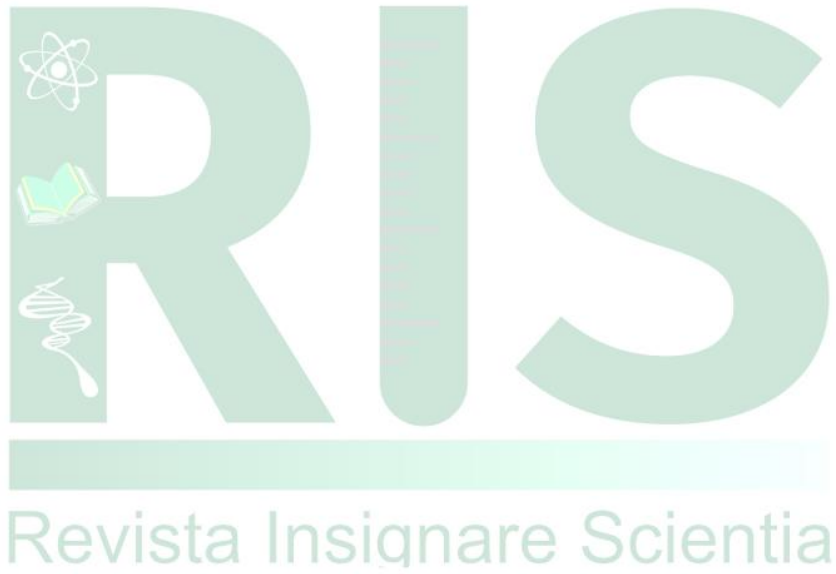

Recebido em: 17/05/2021

Aceite em: $31 / 08 / 2021$ 